\title{
Dopamine Depletion Reorganizes Projections from the Nucleus Accumbens and Ventral Pallidum That Mediate Opioid-Induced Motor Activity
}

\author{
Lynn Churchill, ${ }^{1}$ Mark A. Klitenick, ${ }^{2}$ and Peter W. Kalivas ${ }^{3}$ \\ ${ }^{1}$ Alcohol and Drug Abuse Program, Department of Veterinary and Comparative Anatomy, Pharmacology, and Physiology, \\ Washington State University, Pullman, Washington 99164, 2Department of Behavioral Neuropharmacology, \\ Allelix Neuroscience, South Plainfield, New Jersey 07080, and ${ }^{3}$ Department of Physiology and Neuroscience, Medical \\ University of South Carolina, Charleston, South Carolina 29425
}

\begin{abstract}
Motor activity elicited pharmacologically from the nucleus accumbens by the $\mu$-opioid receptor agonist D-Ala-Tyr-GlyNMePhe-Gly-OH (DAMGO) is augmented in rats sustaining dopamine depletions. GABAergic projections from the nucleus accumbens to ventral pallidum and ventral tegmental area (VTA) are involved because stimulation of $\mathrm{GABA}_{B}$ receptors in the VTA (by baclofen) or GABA $_{A}$ receptors in the ventral pallidum (by muscimol) inhibit the motor response induced by the microinjection of DAMGO into the nucleus accumbens. The present study was done to determine which of these projections is mediating the augmented DAMGO-induced motor activity that follows 6-hydroxydopamine lesions of the nucleus accumbens. The inhibition of DAMGO-induced activation by pallidal injections of muscimol was markedly attenuated in lesioned animals, whereas the inhibition by VTA injections with baclofen was greatly enhanced. A similar switch in emphasis
\end{abstract}

from pallidal to mesencephalic efferents was not observed for dopamine-induced motor activity, because muscimol microinjections inhibited the response elicited by dopamine microinjection into the nucleus accumbens in all subjects. The stimulation of $\mu$-opioid receptors in the ventral pallidum also elicits motor activation, and this is blocked by baclofen microinjection into the VTA. However, after dopamine depletion in the nucleus accumbens, baclofen in the VTA was ineffective in blocking the motor response by DAMGO in the ventral pallidum. These data reveal that dopamine depletion in the nucleus accumbens produces a lesion-induced plasticity that alters the effect of $\mu$-opioid receptor stimulation on efferent projections from the nucleus accumbens and ventral pallidum.

Key words: dopamine lesion; opioid receptor; nucleus accumbens; ventral pallidum; ventral mesencephalon; locomotion
The nucleus accumbens and ventral pallidum (VP) have a pivotal role in regulating exploratory motor behaviors (Mogenson et al., 1980; Le Moal and Simon, 1991). Pharmacological manipulation of dopamine or enkephalin transmission in the nucleus accumbens induces motor activity (for review, see Kalivas et al., 1993a; Mogenson et al., 1993). The nucleus accumbens has a prominent GABAergic projection to the VP (Jones and Mogenson, 1980; Heimer et al., 1991). The motor response elicited by microinjecting the $\mu$-opioid agonist D-Ala-Tyr-Gly-NMePhe-Gly-OH (DAMGO) or dopamine into the accumbens is blocked by stimulating $\mathrm{GABA}_{\mathrm{A}}$ receptors in the VP with the agonist muscimol (Mogenson and Nielsen, 1983; Swerdlow et al., 1984; Patel and Slater, 1988; Austin and Kalivas, 1989). The nucleus accumbens also has a GABAergic projection to the ventral tegmental area (VTA; Kalivas et al., 1993b). The VTA receives additional GABAergic afferents from the VP (Kalivas et al., 1993b). These descending GABAergic afferents synapse primarily on neurons that have $\mathrm{GABA}_{\mathrm{B}}$ receptors (Sugita et al., 1992), and the microinjection of the $\mathrm{GABA}_{\mathrm{B}}$ agonist baclofen into the VTA partly inhibits the motor responses elicited pharmacologically from the

\footnotetext{
Received April 13, 1998; revised June 24, 1998; accepted July 22, 1998.

This work was supported in part by USPHS Grants DA-06612 (to L.C.) and MH-40817, DA-03906, and Research Career Development Award DA-00158 (to P.W.K.). We would like to thank Kari J. Johnson and Patricia Duffy for assistance in the preparation of this paper.

Correspondence should be addressed to Dr. Lynn Churchill at the above address. Copyright (C) 1998 Society for Neuroscience $0270-6474 / 98 / 188074-12 \$ 05.00 / 0$
}

accumbens (Johnson et al., 1996). In addition to the nucleus accumbens, motor activity can be elicited by microinjecting DAMGO or the glutamate receptor agonist AMPA into the VP (Austin and Kalivas, 1990; Shreve and Uretsky, 1991), and the behavioral activation after DAMGO or AMPA microinjection into the VP is abolished by microinjecting baclofen into the VTA (Johnson et al., 1996).

Dopamine in the nucleus accumbens arises from a dense innervation by the ventral mesencephalon, including the VTA and substantia nigra (Swanson, 1982), and dopamine lesions of the mesoaccumbens projection augment the behavioral response produced by DAMGO microinjection into the nucleus accumbens (Kalivas and Bronson, 1985; Churchill and Kalivas, 1992). The mechanisms mediating this lesion-induced behavioral neuroplasticity remain mainly unknown but do not involve alterations in $\mu$-opioid receptor binding (Churchill and Kalivas, 1992). In the present study we hypothesized that the augmented motor response elicited by $\mu$-opioid receptor stimulation in the nucleus accumbens of dopamine-lesioned animals may arise from a change in the relative involvement of efferent projections from the nucleus accumbens to the VP and VTA. Specifically, it was hypothesized that the prepotent role of the projection from the nucleus accumbens to the VP would be superseded by a greater involvement of the projection to the VTA. In addition, a second study was designed to determine whether the obligatory role played by the projection from the VP to the VTA in the motor 


\begin{tabular}{|c|c|c|c|}
\hline Injection sites & Surgery treatment & Pharmacological agents & Behavioral response \\
\hline \multirow[t]{12}{*}{ NA/VP } & 6-OHDA $(n=8)$ & Saline/saline & \\
\hline & & Saline/muscimol & \\
\hline & & DAMGO/saline & Augmented DAMGO response \\
\hline & & DAMGO/muscimol & Muscimol does not block DAMGO \\
\hline & & Dopamine/saline & Augmented dopamine response \\
\hline & & Dopamine/muscimol & Muscimol blocks dopamine \\
\hline & Sham $(n=6)$ & Saline/saline & \\
\hline & & Saline/muscimol & \\
\hline & & DAMGO/saline & \\
\hline & & DAMGO/muscimol & Muscimol blocks DAMGO \\
\hline & & Dopamine/saline & \\
\hline & & Dopamine/muscimol & Muscimol blocks dopamine \\
\hline \multirow[t]{8}{*}{ NA/VTA } & 6-OHDA $(n=9)$ & Saline/saline & \\
\hline & & Saline/baclofen & \\
\hline & & DAMGO/saline & Augmented DAMGO response \\
\hline & & DAMGO/baclofen & Baclofen blocks DAMGO \\
\hline & Sham $(n=11)$ & Saline/saline & \\
\hline & & Saline/baclofen & \\
\hline & & DAMGO/saline & \\
\hline & & DAMGO/baclofen & Baclofen slightly blocks DAMGO \\
\hline \multirow[t]{8}{*}{ VP/VTA } & $6-O H D A(n=7)$ & Saline/saline & \\
\hline & & Saline/baclofen & \\
\hline & & DAMGO/saline & Lesion blunts DAMGO response \\
\hline & & DAMGO/baclofen & Baclofen does not block DAMGO \\
\hline & Sham $(n=7)$ & Saline/saline & \\
\hline & & Saline/baclofen & \\
\hline & & DAMGO/saline & \\
\hline & & DAMGO/baclofen & Baclofen blocks DAMGO \\
\hline \multirow[t]{8}{*}{ VP/VTA } & $6-\mathrm{OHDA}(n=6)$ & Saline/saline & \\
\hline & & Saline/baclofen & \\
\hline & & AMPA/saline & Lesion blunts AMPA response \\
\hline & & AMPA/baclofen & Baclofen blocks AMPA \\
\hline & Sham $(n=6)$ & Saline/saline & \\
\hline & & Saline/baclofen & \\
\hline & & AMPA/saline & \\
\hline & & AMPA/baclofen & Baclofen blocks AMPA \\
\hline \multirow[t]{8}{*}{ Nucleus Accumbens } & $6-O H D A(n=8)$ & Saline + saline & \\
\hline & & Fluphenazine + saline & \\
\hline & & Saline + DAMGO & Augmented DAMGO motor activity \\
\hline & & Fluphenazine + DAMGO & Fluphenazine does not block DAMGO \\
\hline & Sham $(n=7)$ & Saline + saline & \\
\hline & & Fluphenazine + saline & \\
\hline & & Saline + DAMGO & \\
\hline & & Fluphenazine + DAMGO & Fluphenazine does not block DAMGO \\
\hline
\end{tabular}

response elicited by DAMGO microinjection into the VP also was altered by dopamine depletion in the nucleus accumbens.

\section{MATERIALS AND METHODS}

Animal housing and surgery. Male Sprague Dawley rats (250-350 gm) obtained from Simonsen Labs (Gilroy, CA) were housed individually in a temperature- and humidity-controlled environment on a $12 \mathrm{hr}$ light/ dark cycle, with food and water made available ad libitum. Rats were lesioned in the nucleus accumbens, as described by Churchill and Kalivas (1992). Briefly, to block the uptake of 6-hydroxydopamine (6-OHDA) into noradrenergic terminals, we injected the rats with desmethylimipramine $(25 \mathrm{mg} / \mathrm{kg}$, i.p.) $20 \mathrm{~min}$ before inducing analgesia with Equithesin $(2 \mathrm{ml} / \mathrm{kg}$, i.p.). The rats were microinjected with $3 \mu \mathrm{l}$ of $4 \mu \mathrm{g} / \mu \mathrm{l} 6-\mathrm{OHDA}$ (free base in $0.25 \mathrm{mg} / \mathrm{ml}$ ascorbic acid in sterile saline) or sham $(0.25$ $\mathrm{mg} / \mathrm{ml}$ ascorbic acid in sterile saline $)$ over a $12 \mathrm{~min}$ period $(0.2 \mu \mathrm{l} / 50 \mathrm{sec})$ through bilateral 30 gauge cannulae lowered into the nucleus accumbens just below the anterior commissure $[9.4 \mathrm{~mm}$ anteroposterior $(\mathrm{A} / \mathrm{P}), 1.7$ $\mathrm{mm}$ mediolateral $(\mathrm{M} / \mathrm{L})$, and $-0.4 \mathrm{~mm}$ dorsoventral $(\mathrm{D} / \mathrm{V})]$, according to Pellegrino et al. (1979). For behavioral analyses the rats were implanted chronically with bilateral guide cannulae (26 gauge) at $1 \mathrm{~mm}$ above the anterior commissure in the nucleus accumbens $(9.4 \mathrm{~mm} \mathrm{~A} / \mathrm{P}, 1.7 \mathrm{~mm}$ $\mathrm{M} / \mathrm{L}$, and $0.4 \mathrm{~mm} \mathrm{D} / \mathrm{V})$ and/or VP $(7.6 \mathrm{~mm} \mathrm{~A} / \mathrm{P}, 2.2 \mathrm{~mm} \mathrm{M} / \mathrm{L}$, and -0.2 $\mathrm{mm} \mathrm{D} / \mathrm{V})$ and/or VTA $(2.5 \mathrm{~mm} \mathrm{~A} / \mathrm{P}, 0.6 \mathrm{~mm} \mathrm{M} / \mathrm{L}$, and $-2.5 \mathrm{~mm} \mathrm{D} / \mathrm{V})$ relative to the interaural line, according to Pellegrino et al. (1979). After surgery 33 gauge obturators were placed inside the 26 gauge guide cannulae. The rats were monitored for food intake and fed a sweetened diet to enhance the survival rate. 


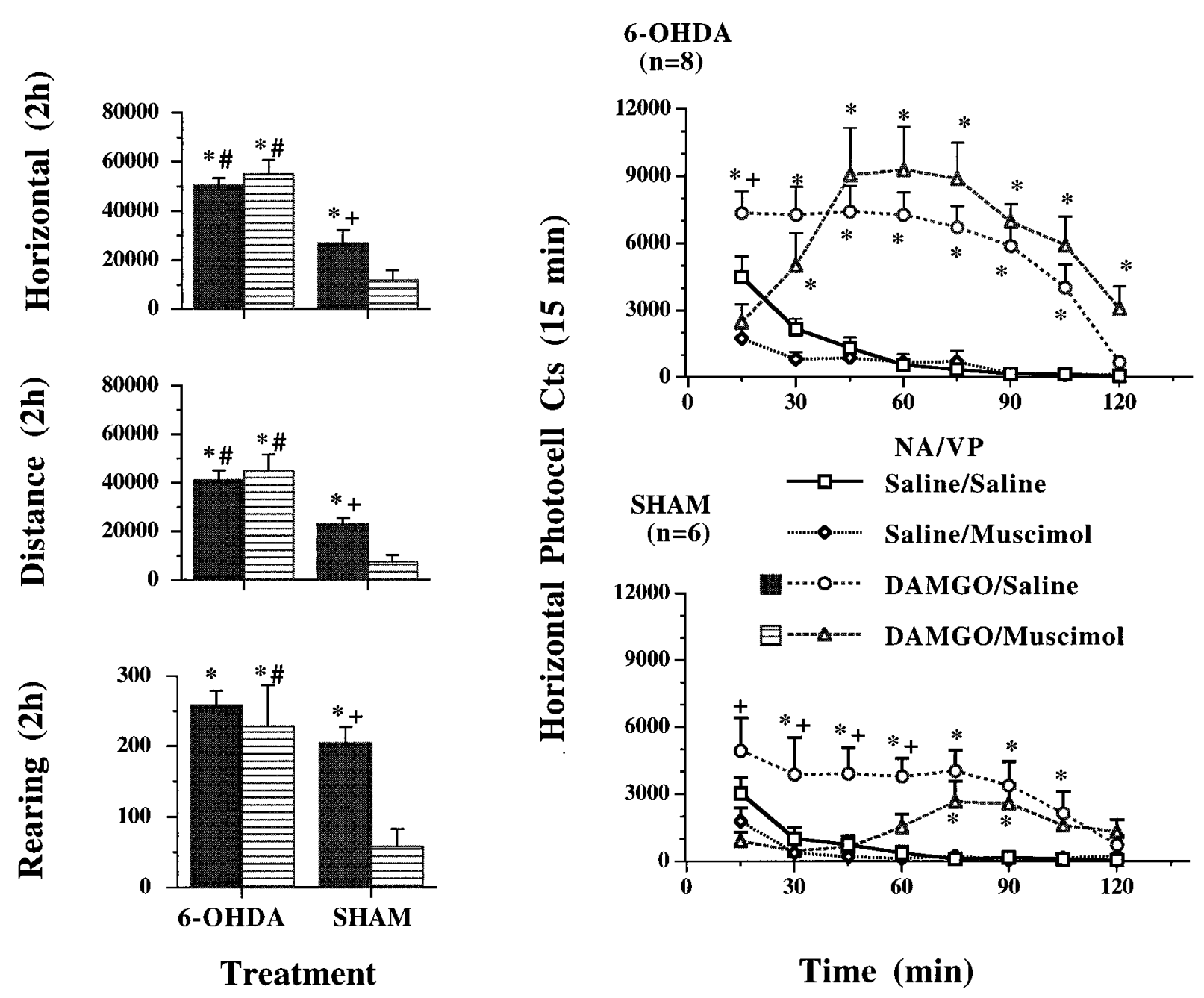

Figure 1. Effect of muscimol $(0.02 \mathrm{nmol} / 0.5 \mu \mathrm{l})$ in the VP on the motor responses elicited by DAMGO $(0.3 \mathrm{nmol} / 0.5 \mu \mathrm{l})$ microinjection into the nucleus accumbens of 6-OHDA-lesioned $(n=8)$ or sham-lesioned $(n=6)$ rats. Behavior, Left, The data are shown as mean \pm SEM photocell counts (horizontal or rearing activity) or centimeters (distance traveled). Each behavior was evaluated for sham- and 6-OHDA-lesioned rats, using a two-way ANOVA with repeated measures over the four treatment groups outlined in Table 1. For illustrative clarity the saline/saline and saline/muscimol groups are not shown. Solid bar, DAMGO/saline; striped bar, DAMGO/muscimol. Horizontal, Surgery: $F_{(1,12)}=34.205, p<0.001$; treatment: $F_{(3,36)}=67.427, p<0.001$; interaction: $F_{(3.36)}=17.615, p<0.001$. Distance, Surgery: $F_{(1,12)}=29.401, p<0.001$; treatment: $F_{(3,36)}=46.501, p<0.001$; interaction: $F_{(3.36)}=12.695$, $p<0.001$. Rearing, Surgery: $F_{(1,12)}=8.404, p=0.0134$; treatment: $F_{(3,36)}=23.446, p<0.001$; interaction: $F_{(3,36)}=3.212, p=0.0343$. Time Course, Right, The data are shown as mean \pm SEM horizontal photocell counts. The behavior was evaluated for either sham- or 6-OHDA-lesioned rats, using a two-way ANOVA with repeated measures over time. The $F$ test values are given for DAMGO microinjections in the nucleus accumbens. 6 - $O H D A(n=8)$, Treatment: $F_{(3,28)}=24.171, p<0.001$; time: $F_{(7,196)}=11.267, p<0.001$; interaction: $F_{(21,196)}=6.09, p<0.001$. Sham $(n=6)$, Treatment: $F_{(3,20)}=9.011$, $p<0.001$; time: $F_{(7,140)}=4.889, p<0.001$; interaction: $F_{(21,140)}=2.564, p<0.001$. ${ }^{*} p<0.05$, comparing DAMGO/drug with saline/drug, using a least significant difference test; ${ }^{+} p<0.05$, comparing drug/saline with drug/muscimol; ${ }^{\#} p<0.05$, comparing 6-OHDA-lesioned with sham-lesioned rats in the same microinjection treatment group.

Pharmacological agents and treatment protocols. At $10 \mathrm{~d}$ after surgery behavioral analyses were performed after microinjection of saline or DAMGO (0.33 nmol/0.5 $\mu \mathrm{l}$; Research Biochemicals, Natick, MA) into the nucleus accumbens 5 min after the microinjection of muscimol $(0.02$ $\mathrm{nmol} / 0.5 \mu \mathrm{l}$; Sigma, St. Louis, MO) into the VP, after baclofen $(0.1$ $\mathrm{nmol} / 0.5 \mu \mathrm{l}$; CIBA-Geigy, Summit, NJ) into the VTA, or after fluphenazine $(9.5 \mathrm{nmol} / 0.5 \mu \mathrm{l}$; Research Biochemicals) into the nucleus accumbens (Table 1). Also, behavioral analyses were performed after saline or DAMGO $(0.33 \mathrm{nmol} / 0.5 \mu \mathrm{l})$ or AMPA $(0.1 \mu \mathrm{g} / 0.5 \mu \mathrm{l}$; Sigma $)$ microinjection into the VP $5 \mathrm{~min}$ after baclofen $(0.1 \mathrm{nmol} / 0.5 \mu \mathrm{l})$ injection into the VTA. Each rat received four trials with each combination of drug. For example, rats with injection cannulae in the nucleus accumbens and VP received the following trials in random order: (1) saline in both nuclei, (2) DAMGO in the accumbens and saline in the VP, (3) saline in the accumbens and muscimol in the VP, and (4) DAMGO in the accumbens and muscimol in the VP. Two additional microinjections were made only in the group with cannulae in the nucleus accumbens and VP. These animals were microinjected with dopamine $(0.05 \mu \mathrm{mol} / 0.5 \mu \mathrm{l}$;
Sigma) into the nucleus accumbens, combined with muscimol $(0.02$ $\mathrm{nmol} / 0.5 \mu \mathrm{l}$ ) or saline into the VP.

Microinjections were made into the brain of a conscious rat by mildly restraining the rat with the hand of the investigator and inserting injection needles (33 gauge) through the guide cannulae. Bilateral infusions were made in the unrestrained rat over 1 min, using a Sage infusion pump. At $20 \mathrm{sec}$ after infusion the injection cannulae were removed, and the obturators were replaced. All drugs were dissolved in sterile isotonic saline.

Behavioral measurements. Spontaneous and pharmacologically induced motor activity was measured with a photocell apparatus (Omnitech Electronics, Columbus, $\mathrm{OH}$ ), as described elsewhere (Austin and Kalivas, 1990). Briefly, horizontal activity was quantified by measuring the number of times that the rats interrupted one of a series of 16 photocell beams located $2 \mathrm{~cm}$ off the cage floor. The distance traveled was quantified by measuring the consecutive breaking of adjacent photocell beams. Rearing was quantified by counting the number of interruptions in eight photocell beams located $18 \mathrm{~cm}$ above the floor. The rats were 

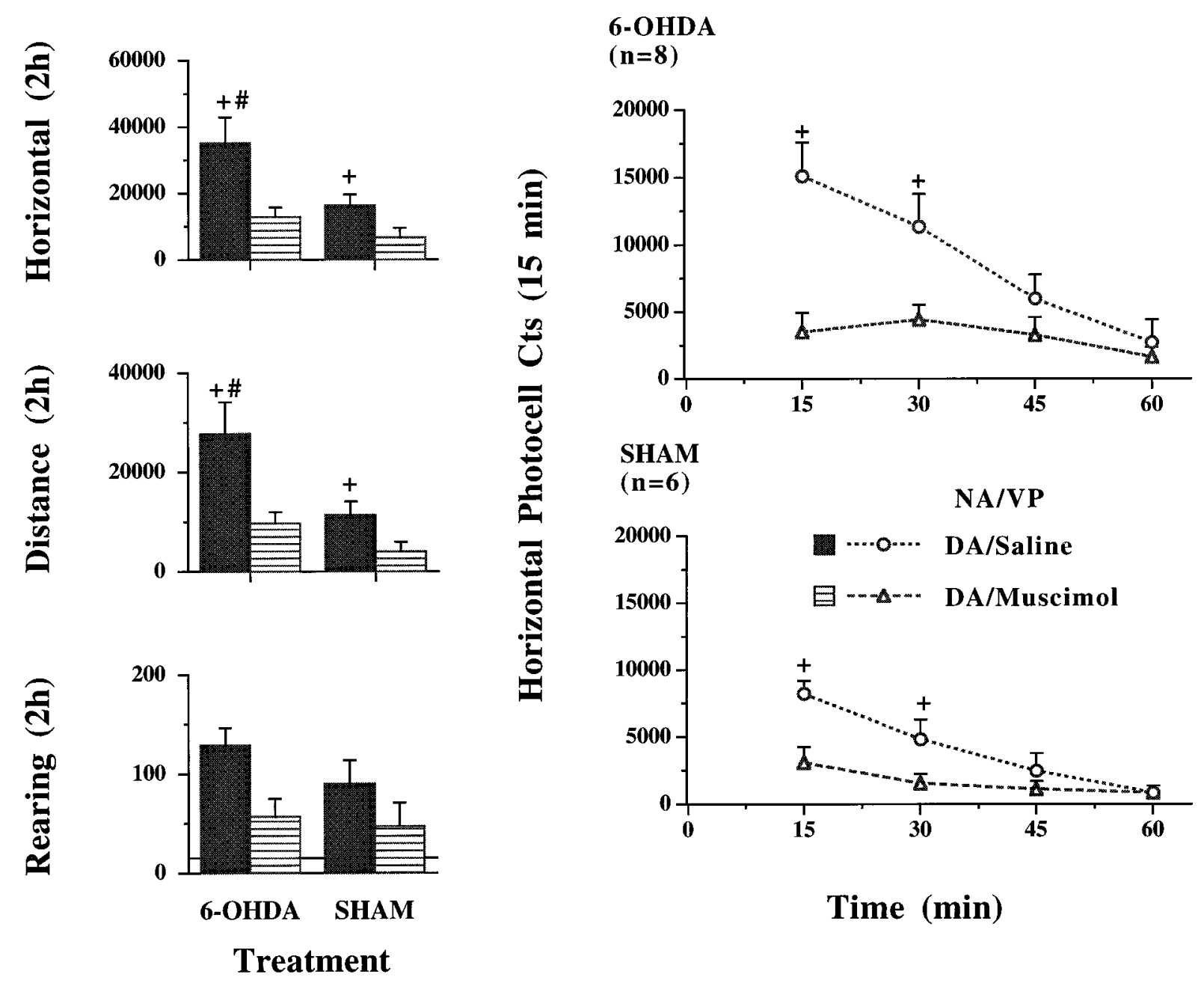

Figure 2. Effect of muscimol $(0.02 \mathrm{nmol} / 0.5 \mu \mathrm{l})$ in the VP on the motor responses elicited by dopamine $(0.05 \mu \mathrm{mol} / 0.5 \mu \mathrm{l}) \mathrm{microinjection}$ into the nucleus accumbens in 6-OHDA-lesioned $(n=8)$ or sham-lesioned $(n=6)$ rats. Only the responses to dopamine/saline and dopamine/muscimol are illustrated in this figure. The responses to saline and muscimol alone are illustrated in Figure 1. Behavior, Left, The data are shown as mean \pm SEM photocell counts (horizontal or rearing activity) or centimeters (distance traveled). Each behavior was evaluated for sham- and 6-OHDA-lesioned rats, using a two-way ANOVA with repeated measures over the treatment groups outlined in Table 1. For illustrative clarity the saline/saline and saline/muscimol groups are not shown. Solid bar, Dopamine/saline; striped bar, dopamine/muscimol. Horizontal, Surgery: $F_{(1,12)}=5.283, p=0.0403$; treatment: $F_{(1,12)}=11.975, p=0.0047$; interaction: $F_{(1,12)}=1.61, p=0.2285$. Distance, Surgery: $F_{(1,12)}=6.198, p=0.0285$; treatment: $F_{(1,12)}=11.669$, $p=0.0051$; interaction: $F_{(1,12)}=1.807, p=0.2037$. Rearing, Surgery: $F_{(1,12)}=0.904, p=0.3604$; treatment: $F_{(1,12)}=4.889, p=0.0472 ;$ interaction: $F_{(1,12)}$ $=0.278, p=0.6076$. Time Course, Right , The data are shown as mean \pm SEM horizontal photocell counts over time. Because the response to dopamine lasted for only $30 \mathrm{~min}$, the time course illustrated is for the first hour of the response. The behavior was evaluated for either sham- or 6-OHDA-lesioned rats, using a two-way ANOVA with repeated measures over time. The $F$ test values are given for DAMGO microinjections in the nucleus accumbens. 6-OHDA $(n=8)$, Treatment: $F_{(3,28)}=10.293, p<0.001$; time: $F_{(3,84)}=9.031, p<0.001$; interaction: $F_{(9,84)}=9.39, p<0.001$. Sham $(n=6)$, Treatment: $F_{(3,20)}=6.239, p=0.0036$; time: $F_{(3,60)}=35.776, p<0.001$; interaction: $F_{(9,60)}=5.123, p<0.001 .{ }^{*} p<0.05$, comparing dopamine/drug with saline/drug, using a least significant difference test; ${ }^{+} p<0.05$, comparing drug/saline with drug/muscimol; ${ }^{\#} p<0.05$, comparing 6-OHDA- and sham-lesioned rats.

preadapted $24 \mathrm{hr}$ before the experiment was started by placing them in the photocell cages for 60 min, making sham microinjections, and returning them to the cages for another hour. On microinjection days the rats were adapted to the photocell cage for $60 \mathrm{~min}$, and behavioral measurements were obtained for $2 \mathrm{hr}$ after the microinjection. After the behavioral analyses the rats were returned to their home cages for a minimum $72 \mathrm{hr}$ intertrial interval.

Histology. After behavioral testing the rats were used randomly for either the quantification of dopamine levels in the nucleus accumbens or histological verification of cannulae placement. Subjects used for the measurement of dopamine had injection cannulae inserted into the guide cannulae just before decapitation to scar the injection site acutely. The nucleus accumbens was dissected on an ice-cooled plate from a $0.75-1$ $\mathrm{mm}$ slice, using a 15 gauge tissue punch. Rats were considered to have injection sites in the nucleus accumbens if damage from the cannula was observed to penetrate the dorsal, but not ventral, edge of the tissue punch. The subjects used for more accurate histological verification were given an overdose of pentobarbital $(100 \mathrm{mg} / \mathrm{kg}$, i.p.) and transcardially perfused with saline, followed by $10 \%$ formalin. Coronal sections $(50-$ $100 \mu \mathrm{m}$ thick) were made with a vibratome. The sections were mounted and stained with cresyl violet; the location of cannula tips was evaluated with reference to the atlas of Paxinos and Watson (1997). Rats with one or both cannulae tips outside of the nucleus accumbens, VP, or ventral VTA or with $<50 \%$ dopamine depletion in the nucleus accumbens were excluded from the data analyses.

Measurement of dopamine. The concentration of dopamine in the nucleus accumbens of sham- or 6-OHDA-lesioned rats was determined by using HPLC with electrochemical detection. After dissection of the nucleus accumbens (see above), bilateral tissue punches were placed in $0.5 \mathrm{ml}$ of mobile phase $(0.1 \mathrm{M}$ trichloroacetic acid, $0.1 \mathrm{M}$ Na-acetate, 0.1 mM EDTA, and $18 \%$ methanol, $\mathrm{pH} 4$, containing $2 \times 10^{-7} \mathrm{M}$ isoproterenol as an internal standard), sonicated, and centrifuged $(13,000 \times g)$ for 

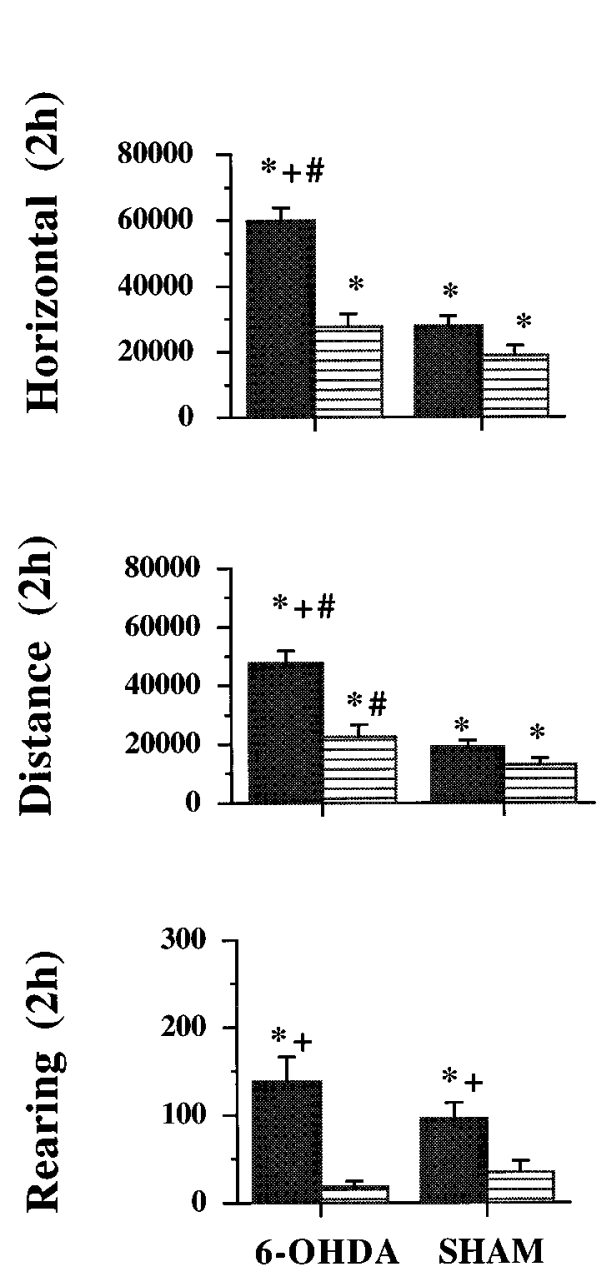

6-OHDA

$(\mathbf{n = 9 )}$

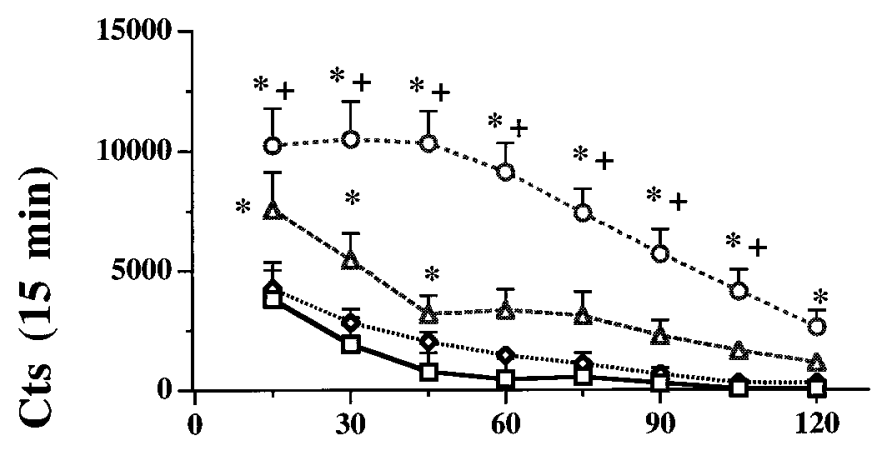

NA/VTA

$(\mathbf{n}=11)$
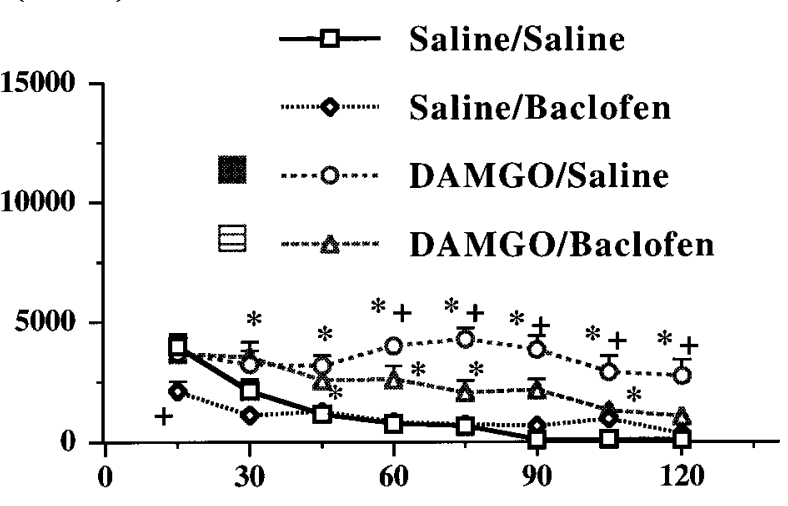

Time (min)

Treatment

Figure 3. Effect of baclofen $(0.1 \mathrm{nmol} / 0.5 \mu \mathrm{l})$ in the VTA on the motor responses elicited by DAMGO $(0.3 \mathrm{nmol} / 0.5 \mu \mathrm{l})$ microinjection into the nucleus accumbens. Behavior, Left, The data are shown as mean \pm SEM photocell counts (horizontal or rearing activity) or centimeters (distance traveled). Each behavior was evaluated for sham-lesioned $(n=11)$ and 6-OHDA-lesioned $(n=7)$ rats, using a two-way ANOVA with repeated measures over the four treatment groups that were outlined in Table 1. For illustrative clarity the saline/saline and saline/baclofen groups are not shown. Solid bar, DAMGO/saline; striped bar, DAMGO/baclofen. Horizontal, Surgery: $F_{(1,12)}=1.409, p=0.2583$; treatment: $F_{(3,36)}=40.335, p<0.001$; interaction: $F_{(3,36)}$ $=6.718, p=0.001$. Distance, Surgery: $F_{(1,18)}=19.169, p<0.001$; treatment: $F_{(3,54)}=48.331, p<0.001$; interaction: $F_{(3.54)}=12.633, p<0.001$. Rearing, Surgery: $F_{(1,18)}=0.039, p=0.8461$; treatment: $F_{(3,54)}=24.275, p<0.001$; interaction: $F_{(3,54)}=2.458, p=0.0727$. Time Course, Right, The data are shown as mean \pm SEM horizontal photocell counts over time. The behavior was evaluated for either 6-OHDA- or sham-lesioned rats, using a two-way ANOVA with repeated measures over time. 6-OHDA $(n=9)$, Treatment: $F_{(3,32)}=30.311, p<0.001$; time: $F_{(7,224)}=33.875, p<0.001$; interaction: $F_{(21,224)}=$ 3.181, $p<0.001$. Sham $(n=11)$, Treatment: $F_{(3,40)}=22.652, p<0.001$; time: $F_{(7,280)}=14.874, p<0.001$; interaction: $F_{(21,280)}=2.982, p<0.001 .{ }^{*} p<$ 0.05 , comparing DAMGO/drug with saline/drug, using a least significant difference test; ${ }^{+} p<0.05$, comparing drug/saline with drug/baclofen; ${ }^{\#} p<0.05$, comparing 6-OHDA- and sham-lesioned rats.

2 min. The supernatant was removed for analysis on the HPLC while the pellet was assayed for protein content, using the Lowry method. The biogenic amines were separated on a $25 \mathrm{~mm}$ ODS C-18 reverse-phase column (Bioanalytical Systems, Lafayette, IN) and oxidized at $0.7 \mathrm{~V}$. The concentration of biogenic amines was calculated from a standard curve (from $10^{-12}$ to $10^{-10} \mathrm{~mol}$ ). The detection limit was $3 \times 10^{-13} \mathrm{~mol}$.

Statistics. Total horizontal activity, the distance traveled, and rearing were evaluated by using a two-way ANOVA, with one factor being the lesion group and the other being repeated measures over treatment. If a significant interaction was observed, a least significant difference test was used (Milliken and Johnson, 1984). If there was no significant interaction but a significant treatment effect was present, then a one-way ANOVA with repeated measures within each lesion group was used, followed by a Scheffé's test for multiple comparisons between treatments. The time course data were evaluated separately for the sham- or 6-OHDAlesioned rats with a two-way ANOVA, with one factor being treatment and the other being a repeated measures over time, followed by a least significant difference test.

\section{RESULTS}

\section{Effect of muscimol in the VP on locomotion induced from the nucleus accumbens}

Figure 1 shows that DAMGO $(0.33 \mathrm{nmol})$ microinjection into the nucleus accumbens significantly elevates all three measures of motor activity over the $120 \mathrm{~min}$ after injection into the nucleus accumbens in both the sham and 6-OHDA treatment groups. However, the DAMGO-induced elevation in horizontal photocell counts and distance traveled was greater in the lesioned, as compared with the sham, group. Muscimol (0.02 nmol) microinjection into the VP significantly reduced the motor response to DAMGO in the sham treatment group. In contrast, muscimol was without effect on the total behavioral response to DAMGO in 6-OHDA-lesioned subjects. The time course data for the hori- 


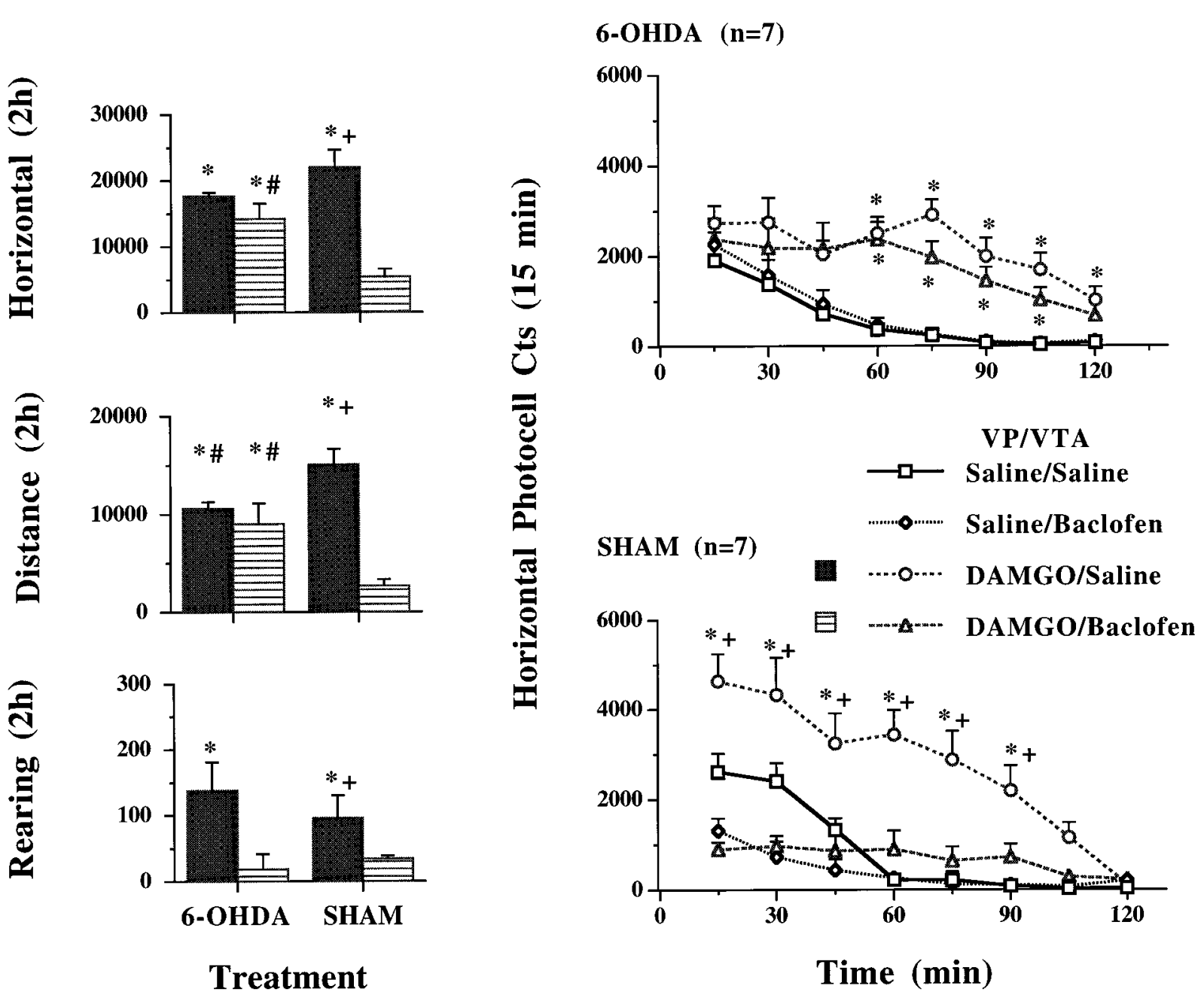

Figure 4. Effect of baclofen $(0.1 \mathrm{nmol} / 0.5 \mu \mathrm{l})$ in the VTA on the motor responses elicited by DAMGO $(0.3 \mathrm{nmol} / 0.5 \mu \mathrm{l})$ microinjection into the VP. Behavior, Left, The data are shown as mean \pm SEM photocell counts (horizontal or rearing activity) or centimeters (distance traveled). Each behavior was evaluated for either sham-lesioned $(n=7)$ and 6-OHDA-lesioned $(n=8)$ rats, using a two-way ANOVA with repeated measures over treatment. For illustrative clarity the saline/saline and saline/baclofen groups are not shown. Solid bar, DAMGO/saline; striped bar, DAMGO/baclofen. Horizontal, Surgery: $F_{(1,12)}=1.409, p=0.2583$; treatment: $F_{(3,36)}=40.335, p<0.001$; interaction: $F_{(3,36)}=6.718, p=0.001$. Distance, Surgery: $F_{(1,12)}=0.476, p=$ 0.5034; treatment: $F_{(3,36)}=38.5, p<0.001$; interaction: $F_{(3,36)}=8.917, p<0.001$. Rearing, Surgery: $F_{(1,12)}=0.01, p=0.9234$; treatment: $F_{(3,36)}=18.04$, $p<0.001$; interaction: $F_{(3,36)}=2.01, p=0.1299$. Time Course, Right, The data are shown as mean \pm SEM horizontal photocell counts over time. The behavior was evaluated for either 6-OHDA- or sham-lesioned rats, using a two-way ANOVA with repeated measures over time. 6-OHDA $(n=7)$, Treatment: $F_{(3,24)}=15.477, p<0.001$; time: $F_{(7,168)}=14.489, p<0.001$; interaction: $F_{(21,168)}=1.284, p=0.1918$. Sham $(n=7)$, Treatment: $F_{(3,24)}=$ $30.862, p<0.001$; time: $F_{(7,168)}=24.281, p<0.001$; interaction: $F_{(21,168)}=4.728, p<0.001 .{ }^{*} p<0.05$, comparing DAMGO/drug with saline/drug; ${ }^{+} p<$ 0.05 , comparing drug/saline with drug/baclofen; ${ }^{*} p<0.05$, comparing 6-OHDA- and sham-lesioned rats.

zontal photocell counts are shown in Figure 1 and reveal that in lesioned rats muscimol did produce a significant reduction in the DAMGO response during the first $15 \mathrm{~min}$ after injection but was ineffective thereafter. In contrast, the response to DAMGO in sham animals was blocked over the first 60 min after injection by muscimol. Both the total photocell count measure of motor activity and the time course reveal that muscimol alone did not alter motor behavior significantly.

Dopamine depletion in the nucleus accumbens also augments the motor response produced by stimulating dopamine receptors (Breese et al., 1987). To determine whether the reduced effectiveness of muscimol in lesioned rats was selective for DAMGOinduced motor activity, dopamine was microinjected into the nucleus accumbens, and motor activity was monitored in the presence or absence of muscimol in the VP. Figure 2 shows that dopamine $(0.05 \mu \mathrm{mol})$ increased horizontal photocell counts and the distance traveled in both treatment groups and that the stimulant response was greater in the lesioned than in the sham subjects. Muscimol $(0.02 \mathrm{nmol})$ in the VP significantly blocked dopamine-induced motor activity in both treatment groups for the duration of the response (i.e., for $30 \mathrm{~min}$ after injection).

\section{Effect of baclofen in the VTA on DAMGO-induced behavior from the nucleus accumbens}

As with the previous data set, the increase in total horizontal photocell counts and in the distance traveled that was elicited by DAMGO $(0.33 \mathrm{nmol})$ microinjection into the nucleus accumbens was greater in lesioned animals as compared with sham subjects (Fig. 3). When activity over the 120 min after injection was examined, baclofen $(0.1 \mathrm{nmol})$ microinjection into the VTA of sham rats was found not to alter the DAMGO-induced increase in horizontal counts or distance traveled, but it did reduce the 

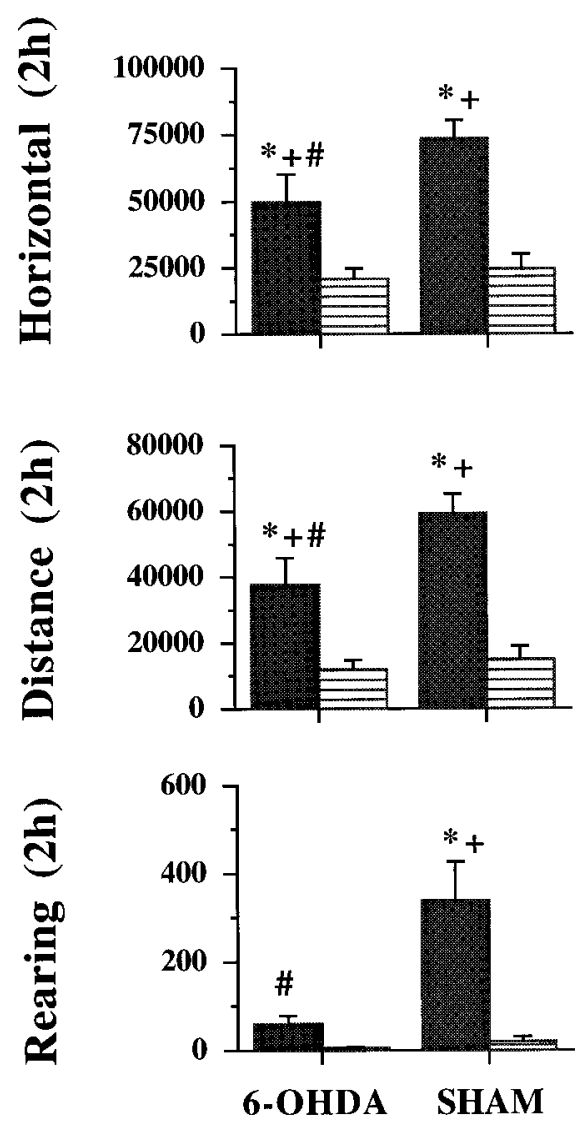

Treatment

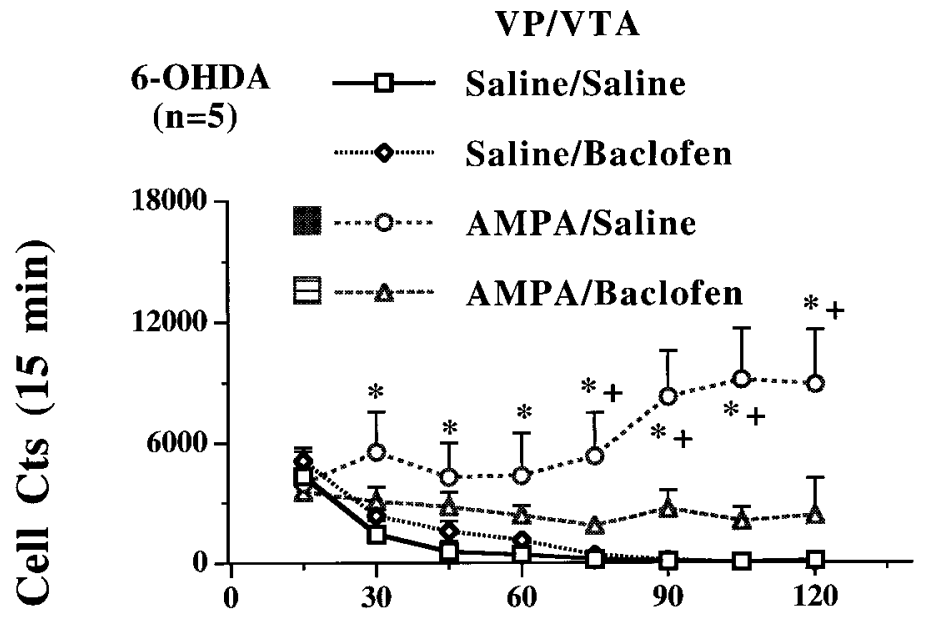

SHAM (n=6)

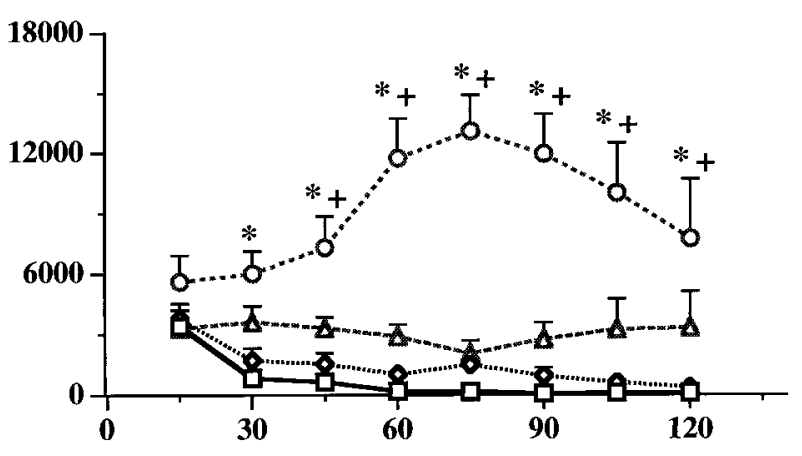

Time (min)

Figure 5. Effect of baclofen $(0.1 \mathrm{nmol} / 0.5 \mu \mathrm{l})$ in the VTA on the motor responses elicited by AMPA $(0.1 \mu \mathrm{gm} / 0.5 \mu \mathrm{l})$ microinjection into the VP. Behavior, Left, The data are shown as mean \pm SEM photocell counts (horizontal or rearing activity) or centimeters (distance traveled). Each behavior was evaluated for sham-lesioned $(n=6)$ or 6-OHDA-lesioned $(n=5)$ rats, using a two-way ANOVA with repeated measures over treatment. For illustrative clarity the saline/saline and saline/baclofen groups are not shown. Solid bar, AMPA/saline; striped bar, AMPA/baclofen. Horizontal, Surgery: $F_{(1,9)}=2.586, p=0.1423$; treatment: $F_{(3,27)}=48.605, p<0.001$; interaction: $F_{(3,27)}=2.563, p=0.0756$. Distance, Surgery: $F_{(1,9)}=2.82, p=0.1274 ;$ treatment: $F_{(3,27)}=56.47, p<0.001$; interaction: $F_{(3,27)}=0.0211$. Rearing, Surgery: $F_{(1,9)} 4.464, p=0.0638$; treatment: $F_{(3,27)}=12.363, p<0.001$; interaction: $F_{(3,27)}=7.679, p<0.001$. Time Course, Right, The data are shown as mean \pm SEM horizontal photocell counts over time. The behavior was evaluated for either 6-OHDA- or sham-lesioned rats, using a two-way ANOVA with repeated measures over time. 6-OHDA $(n=5)$, Treatment: $F_{(3,16)}=10.946, p<0.001$; time: $F_{(7,112)}=2.042, p=0.0558$; interaction: $F_{(21,112)}=2.618, p<0.001$. Sham $(n=6)$, Treatment: $F_{(3,20)}=41.626, p<$ 0.001 ; time: $F_{(7,140)}=0.905, p=0.5049$; interaction: $F_{(21,140)}=2.935, p<0.001 .{ }^{*} p<0.05$, comparing AMPA/drug with saline/drug; ${ }^{+} p<0.05$, comparing drug/saline with drug/baclofen; ${ }^{*} p<0.05$, comparing 6-OHDA- and sham-lesioned rats.

increase in rearing. By contrast, baclofen significantly blocked the expression of all three DAMGO-induced behaviors in dopaminedepleted animals. The time course data for horizontal activity also illustrated in Figure 3 demonstrate that in lesioned rats DAMGO significantly elevated motor activity as compared with that in saline-treated subjects for 115 min after microinjection and that baclofen antagonized this effect over the entire time course. In the sham group DAMGO alone significantly elevated motor activity between 30 and $120 \mathrm{~min}$ after injection, and baclofen reduced the DAMGO-induced activity significantly between 60 and 120 min after injection. However, the reduction was only partial, because baclofen plus DAMGO was also significantly different from saline plus baclofen at 15, 30, and 60-90 min after injection. Baclofen alone significantly reduced horizontal photocell counts, as compared with those after saline injection, in the first 15 min of the experiment with sham lesioned subjects, but it did not alter the saline response in lesioned rats.

\section{Effect of baclofen in the VTA on DAMGO-induced behavior from the VP}

DAMGO microinjection into the VP elicited a significant elevation in all three measures of motor activation in both treatment groups (Fig. 4). The increase in the distance traveled was blunted significantly in the lesion as compared with that in the sham treatment group. Baclofen microinjection into the VP blocked the capacity of DAMGO to elevate all three measures of motor activity in the sham treatment group. By contrast, baclofen was effective only in reducing DAMGO-induced rearing in the lesioned animals and did not alter horizontal photocell counts or distance traveled. The time course data in Figure 4 reveal that DAMGO elevated photocell counts in sham animals for the first 90 min after injection and that baclofen reduced this response over the entire time course of the stimulant effect. In lesioned rats the DAMGO-induced increase was between 60 and 105 min after 

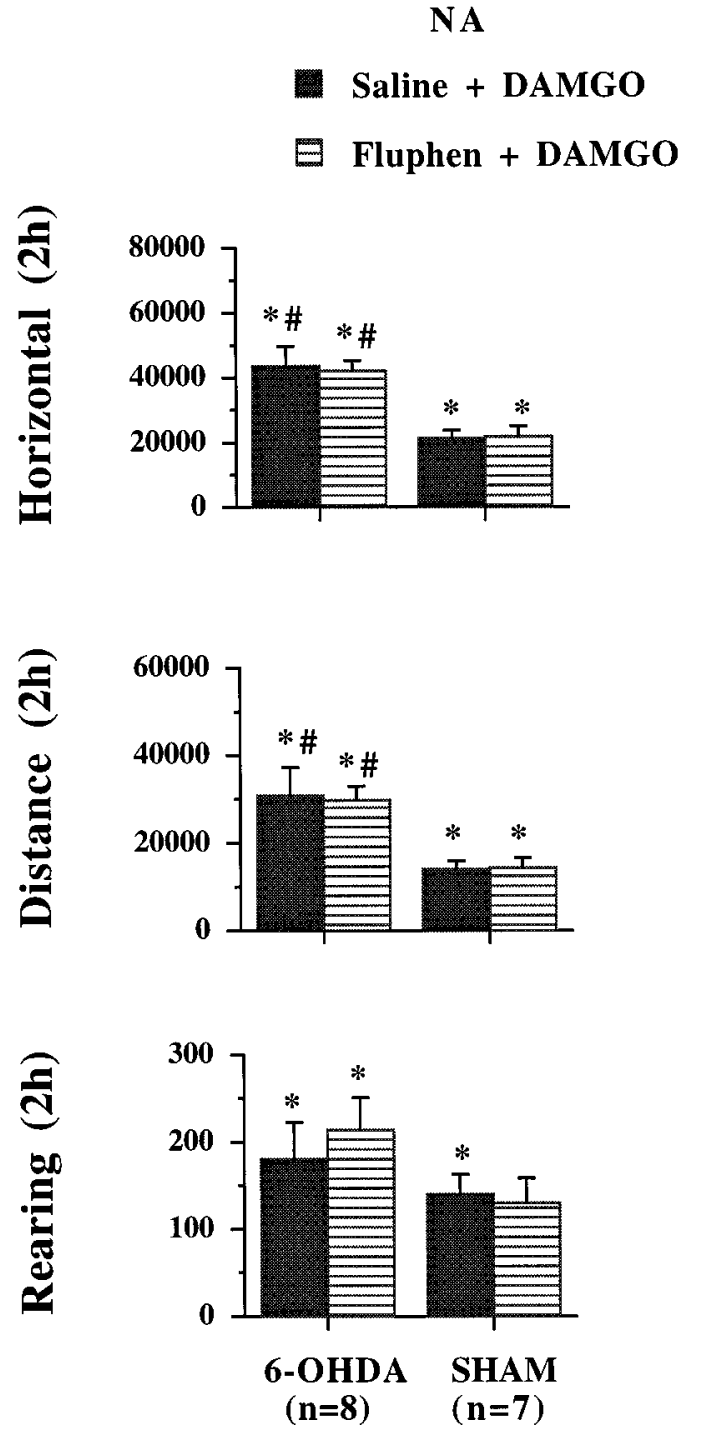

\section{Treatment}

Figure 6. Effect of fluphenazine $(9.5 \mathrm{nmol} / 0.5 \mu \mathrm{l})$ microinjections in the nucleus accumbens $5 \mathrm{~min}$ before DAMGO microinjections in the nucleus accumbens. The data are shown as mean \pm SEM photocell counts (horizontal or rearing activity) or centimeters (distance traveled). Each behavior was evaluated for sham-lesioned $(n=7)$ and 6-OHDA-lesioned $(n=8)$ rats, using a two-way ANOVA with repeated measures over treatment. Horizontal, Surgery: $F_{(1,13)}=19.035, p<0.001$; treatment: $F_{(3,39)}=48.106, p<0.001$; interaction: $F_{(3,39)}=9.382, p<0.001$. Distance, Surgery: $F_{(1,13)}=11.029, p=0.0055$; treatment: $F_{(3,39)}=27.353, p<$ 0.001; interaction: $F_{(3,39)}=5.797, p=0.0022$. Rearing, Surgery: $F_{(1,13)}=$ $1.731, p=0.211$; treatment: $F_{(3,39)}=13.082, p<0.001$; interaction: $F_{(3,39)}$ $=1.645, p=0.1948 . * p<0.05$, comparing DAMGO/drug with saline/ drug; ${ }^{+} p<0.05$, comparing drug/saline with drug/fluphenazine; ${ }^{\#} p<$ 0.05 , comparing 6-OHDA- and sham-lesioned rats.

injection. Baclofen did not alter significantly the time course of the DAMGO-induced motor response in lesioned rats. Baclofen alone significantly reduced motor activity during the first $15 \mathrm{~min}$ after injection in the sham, but not in the lesion treatment, group.

\section{Effect of baclofen in the VTA on AMPA-induced behavior from the VP}

The stimulation of the AMPA glutamate receptor subtype in the VP increases motor activity (Shreve and Uretsky, 1991), and this stimulant response is blocked by baclofen microinjection into the VTA (Johnson et al., 1996). Figure 5 shows that AMPA microinjection into the VP elevated all three measures of motor activity in sham subjects. Although a significant elevation also was observed in horizontal photocell counts and in the distance traveled in lesioned animals, the distance traveled was reduced significantly as compared with that in sham subjects. Furthermore, AMPA did not induce rearing in lesioned rats. Baclofen microinjection into the VTA inhibited the AMPA-induced increase in the behavioral measures from both the dopaminedepleted and sham groups. The time course data illustrated in Figure 5 demonstrate that AMPA significantly enhanced horizontal activity from 30 to 120 min after microinjection into either dopamine-lesioned or sham subjects. Baclofen microinjected into the VTA abolished the horizontal activity induced by AMPA from 75 to $120 \mathrm{~min}$ in the lesioned rats and from 45 to $120 \mathrm{~min}$ in the sham subjects.

\section{Effect of fluphenazine in the nucleus accumbens on DAMGO-induced behavior in the nucleus accumbens}

Because baclofen microinjected into the ventral mesencephalon inhibits mesoaccumbens dopaminergic as well as GABAergic neurons (Olpe et al., 1977; Lacey et al., 1988), the inhibition of DAMGO-induced motor activity by baclofen may arise from inhibiting the dopamine projections remaining after lesions in the nucleus accumbens. To test this hypothesis, we microinjected the dopamine receptor antagonist fluphenazine into the nucleus accumbens 5 min before microinjecting DAMGO into the nucleus accumbens. The dose of fluphenazine that was used $(9.5 \mathrm{nmol} /$ side) was shown previously to inhibit motor activity elicited by systemic amphetamine, novelty, and intra-VTA administration of neuropeptides (Kalivas et al., 1983; Hooks and Kalivas, 1994). Figure 6 shows that DAMGO induced a significant increase in horizontal activity and distance in both sham and lesioned rats and a significant increase in rearing in lesioned rats. DAMGOinduced horizontal photocell counts and the distance traveled were greater in the lesioned, as compared with the sham, animals. Fluphenazine microinjection into the nucleus accumbens $5 \mathrm{~min}$ before intra-accumbens DAMGO was administered did not block the increase in total horizontal photocell counts, the distance traveled, and the number of vertical movements in either 6-OHDA-lesioned or sham rats. Likewise, the time course data (not shown) did not reveal any significant differences between DAMGO-induced augmentation in the presence or in the absence of fluphenazine.

\section{Histology and dopamine depletion}

The nucleus accumbens from randomly selected rats was examined for tissue content of dopamine while the remaining rats were processed for histological verification of cannulae placement. The location of microinjection cannulae in the nucleus accumbens was primarily in the ventral nucleus accumbens shell and core (Fig. 7). The placement of cannulae was generally in the dorsal half of the VP; in the ventral mesencephalon the cannulae tips were located throughout the VTA and sometimes near the medial substantia nigra, pars compacta. In each of the experiments in which the dopamine levels were measured in the nucleus accumbens, 6-OHDA-treated subjects had dopamine levels reduced by $\sim 80 \%$ in comparison with those in sham-lesioned rats, whereas the serotonin levels were not altered significantly (Table 2). The concentration of norepinephrine was reduced significantly to $51 \%$ 

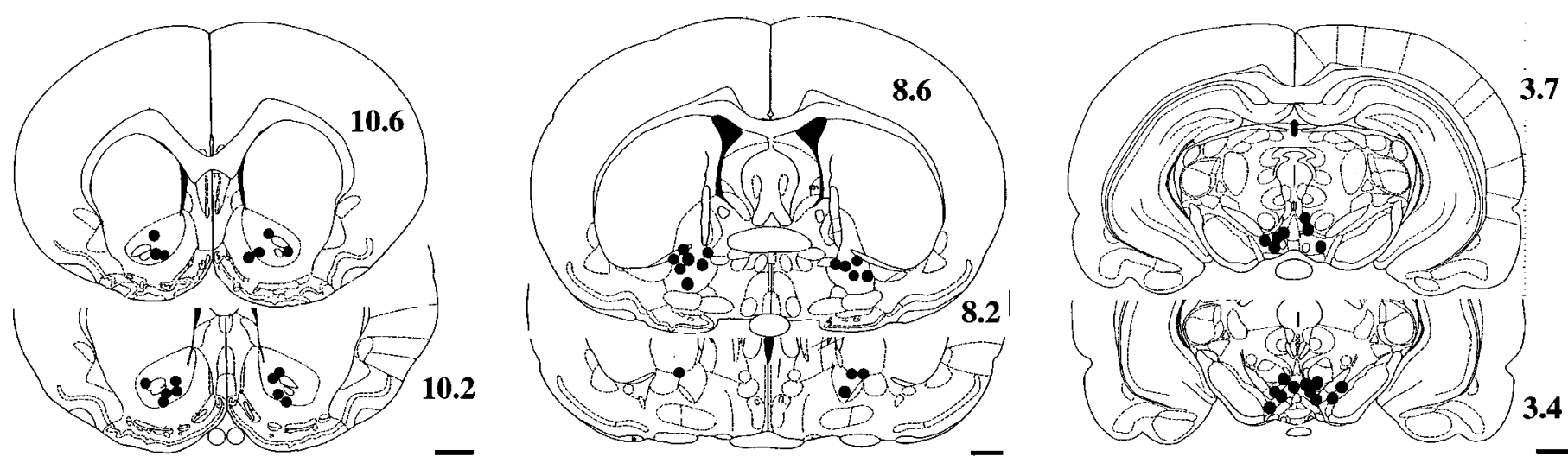

Figure 7. Location of microinjection cannulae in the nucleus accumbens (left), VP (middle), and ventral mesencephalon (right). The location of the microinjection cannulae within the nucleus accumbens and VP is illustrated for the dopamine-lesioned rats used in Figures 1 and 2, respectively, and the location in the ventral mesencephalon is illustrated for the dopamine-lesioned rats used in Figure 3. The drawings are based on the atlas of Paxinos and Watson (1997). The interaural distances are indicated on each slice. Scale bar, $1 \mathrm{~cm}$.

Table 2. Dopamine, serotonin and norepinephrine (NE) levels in the nucleus accumbens for each of the following experiments:

NA/VP-DAMGO/muscimol (DG/Mus), NA/VTA-DAMGO/baclofen (DG/Bac), and NA-DAMGO/fluphenazine (DG/Fln)

\begin{tabular}{|c|c|c|c|c|c|}
\hline \multirow[b]{2}{*}{ Experiment } & \multirow[b]{2}{*}{ Treatment } & \multirow[b]{2}{*}{$n$} & \multicolumn{3}{|c|}{ Concentration ( $\%$ of sham-lesioned) } \\
\hline & & & Dopamine & Serotonin & $\mathrm{NE}$ \\
\hline \multirow[t]{2}{*}{ NA/VP-DG/Mus } & Sham & 4 & $100 \pm 17.0$ & $100 \pm 5.3$ & $100 \pm 13.1$ \\
\hline & 6-OHDA & 6 & $20.9 \pm 4.8^{*}$ & $103.8 \pm 7.1$ & $50.9 \pm 9.9^{*}$ \\
\hline \multirow[t]{2}{*}{ NA/VTA-DG/Bac } & Sham & 8 & $100 \pm 6.6$ & $100 \pm 5.2$ & $100 \pm 15.7$ \\
\hline & 6-OHDA & 6 & $21.6 \pm 10.5^{*}$ & $98.4 \pm 9.7$ & $67.5 \pm 11.1$ \\
\hline \multirow[t]{2}{*}{ NA-DG/Fln } & Sham & 7 & $100 \pm 12.6$ & $100 \pm 14.2$ & $100 \pm 24.9$ \\
\hline & 6-OHDA & 8 & $18.2 \pm 6.2^{*}$ & $75.4 \pm 4.7$ & $78.9 \pm 11.3$ \\
\hline
\end{tabular}

The data are expressed as a percentage of the sham-lesioned rats within each study.

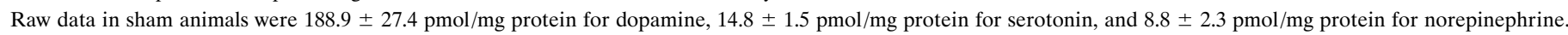
${ }^{*} p<0.05$, comparing sham with 6-OHDA-lesioned rats, using Student's $t$ test.

in the first experiment, but no significant reductions were measured in the other experiments.

\section{DISCUSSION}

Dopamine depletion in the nucleus accumbens augments the behavioral response elicited by $\mu$-opioid receptor stimulation in the nucleus accumbens (Kalivas and Bronson, 1985; Stinus et al., 1985; Churchill and Kalivas, 1992), and the present report demonstrates that this behavioral plasticity is associated with the functional reorganization of a circuit that includes the nucleus accumbens, VP, and VTA. The motor activation after the stimulation of $\mu$-opioid receptors in the nucleus accumbens with DAMGO involves projections to the VP and, to a lesser extent, efferents to the VTA (Austin and Kalivas, 1989; Johnson et al., 1996). After dopamine depletion the majority of the stimulant response involved projections to the VTA, because stimulating $\mathrm{GABA}_{\mathrm{B}}$ receptors in the VTA with baclofen abolished the entire response to DAMGO. By contrast, the involvement of pallidal efferents was reduced because muscimol in the VP was relatively ineffective. Not only did the lesion alter the circuitry mediating behavioral output that was initiated from the nucleus accumbens, it also altered output that was elicited from the VP. In shamlesioned subjects the motor response elicited by DAMGO in the VP was abolished by baclofen in the VTA, but after dopamine depletion in the nucleus accumbens baclofen in the VTA was without effect. These alterations in functional circuitry appeared to be selective for $\mu$-opioid receptor stimulation. After dopamine depletion in the nucleus accumbens, muscimol in the VP continued to antagonize the motor response elicited by dopamine in the nucleus accumbens, and baclofen in the VTA persisted in blocking the motor response after AMPA in the VP.

The discussion below describes possible synaptic and cellular mechanisms that contribute to the lesion-induced changes in circuitry that may be mediating the altered behavioral responses to DAMGO. Because of a relative dearth of investigations into the consequences of dopamine lesions in the nucleus accumbens, the discussion often relies on studies that examined the effect of dopamine depletion in the striatum. Although the spiny neurons in the striatum and nucleus accumbens have parallel projections to the pallidum and ventral mesencephalon (Joel and Weiner, 1994), there exist anatomical and functional distinctions between these structures (Groenewegen et al., 1996). Nonetheless, a comparison of the nucleus accumbens with the more abundant striatal literature reveals general overlap in the impact of dopamine depletion on the respective efferent circuits.

\section{Alterations in the circuit after dopamine depletion in the nucleus accumbens/striatum}

The spiny neurons projecting from the striatum to the globus pallidus are chemically distinct from those projecting to the substantia nigra. The pallidal projection contains GABA, enkephalin, and D2 receptors, whereas the mesencephalic projection contains GABA, substance $\mathrm{P}$, and D1 receptors (Gerfen and Young, 1988). The corresponding spiny neuron output from the 

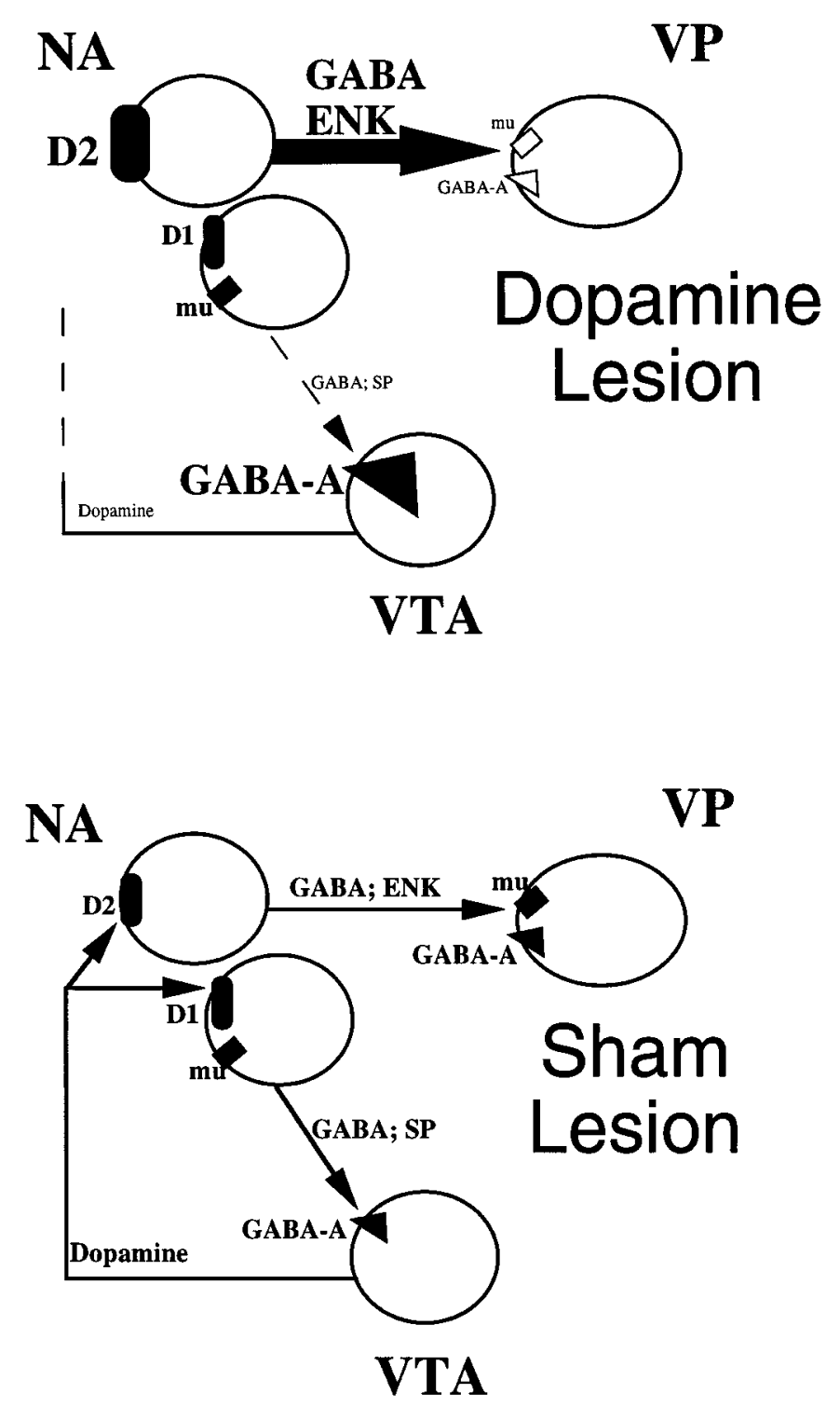

Figure 8. Model depicting the neural plasticity induced by a dopamine lesion in the nucleus accumbens $(N A)$ on the circuit containing the $N A$, $V P$, and $V T A$. Many of the changes that are shown are extrapolated from studies examining striatal dopamine depletion. After dopamine depletion in the $N A$ /striatum there is an increase in neurotransmission in spiny cells projecting to the pallidum. This is evident by lesion-induced increases in enkephalin (ENK; Voorn et al., 1994) and $\mathrm{GAD}_{67}$ synthesis (Soghomonian et al., 1992) and D2 receptors (Creese and Snyder, 1979) as well as by elevated extracellular GABA (Bourdelais and Kalivas, 1992) and reduced $\mathrm{GABA}_{\mathrm{A}}$ (Pan et al., 1985) and $\mu$-opioid receptors $(\mathrm{mu})$ (Delfs et al., 1994) (after chronic dopamine receptor blockade) in the pallidum. Conversely, neurotransmission in spiny cells projecting to the $V T A$ / substantia nigra is reduced, as evidenced by decreases in substance $\mathrm{P}(S P)$ synthesis without a change in $D 1$ receptors in the $N A$ /striatum (Breese et al., 1987; Gerfen et al., 1991; Delfs et al., 1995) as well as by reduced extracellular levels of substance $\mathrm{P}$ and increased $\mathrm{GABA}_{\mathrm{A}}$ receptor density in the $V T A$ /substantia nigra (Pan et al., 1985; Lindefors et al., 1989; Churchill et al., 1992). Increases in transmission are indicated by larger letter, symbol, or line size, whereas decreases are indicated by reduced letter size, open symbols, or dashed lines.

nucleus accumbens is somewhat less differentiated. The projection to the VTA contains exclusively GABA/substance P/D1 receptors, whereas the output to the VP contains both types of spiny neurons (Kawaguchi et al., 1990; Lu et al., 1998). The literature suggests that dopamine depletion in the nucleus accumbens/striatum selectively upregulates neurotransmission in the GABA/enkephalin/D2 spiny cells, although not affecting or downregulating the GABA/substance P/D1 neurons. For example, the synthesis of enkephalin and D2 receptors is increased (Creese and Snyder, 1979; Voorn et al., 1994), whereas substance $\mathrm{P}$ synthesis is reduced and D1 receptors are unchanged by dopamine depletion (Breese et al., 1987; Gerfen et al., 1991). Moreover, dopamine depletion elevates the synthesis of the isoform $\left(\mathrm{GAD}_{67}\right)$ of glutamate decarboxylase that is regulated by D2 receptors and does not affect synthesis of the isoform $\left(\mathrm{GAD}_{65}\right)$ regulated by D1 receptors (Soghomonian et al., 1992; Laprade and Soghomonian, 1995). Also, extracellular GABA levels are elevated in the VP, whereas substance P levels in the substantia nigra are reduced by striatal/accumbens dopamine depletion (Lindefors et al., 1989; Bourdelais and Kalivas, 1992). Postsynaptic changes in $\mathrm{GABA}_{\mathrm{A}}$ receptor binding also reflect distinct changes in GABAergic innervation of the VP and VTA, because dopamine lesions elevate $\mathrm{GABA}_{\mathrm{A}}$ receptor density in the VTA/ substantia nigra while simultaneously lowering $\mathrm{GABA}_{\mathrm{A}}$ binding in the pallidum (Pan et al., 1985; Churchill et al., 1992). Finally, although $\mu$-opioid receptor binding is not altered in the nucleus accumbens by dopamine lesions (Churchill and Kalivas, 1992), $\mu$-opioid mRNA levels are reduced in the pallidum after chronic dopamine receptor blockade (Delfs et al., 1994), perhaps as a result of increased enkephalin transmission in the striatopallidal pathway.

Figure 8 shows a model of the lesion-induced alterations that culminate in an increase in inhibitory tone in the pallidum and a decrease in the VTA. Herein lies a possible explanation for the present findings. The increase in GABA transmission and the ensuing reduction in $\mathrm{GABA}_{\mathrm{A}}$ binding density may render the stimulation of $\mathrm{GABA}_{\mathrm{A}}$ receptors by muscimol less effective in reducing the motor response by DAMGO in the nucleus accumbens of lesioned rats. Conversely, the potential decrease in transmission in the mesencephalic projection may produce a corresponding upregulation in sensitivity to baclofen in the VTA of lesioned subjects. However, the lesion-induced changes in GABAergic tone in the VP and VTA do not explain why muscimol in the VP remained highly effective at reducing the motor response elicited by dopamine in the nucleus accumbens of lesioned rats. This argues that lesion-induced alterations within the nucleus accumbens also may play a role in the apparent switch from the pallidal to the mesencephalic efferents that are mediating DAMGO-induced motor activity.

\section{Synaptic organization in the nucleus accumbens}

Electrophysiological studies reveal that opioids mainly inhibit synaptic input (Yuan et al., 1992). $\mu$-Opioid receptors preferentially colocalize with the GABA/substance P/D1 population of spiny cells (Guttenberg et al., 1996), and electron microscopic studies reveal that $\mu$-opioid receptors are located adjacent to enkephalin terminals (Svingos et al., 1996). Therefore, the upregulated enkephalin synthesis in the nucleus accumbens of dopamine-depleted subjects will provide greater inhibitory tone to the GABA/substance P/D1 neurons projecting to the mesencephalon and may mediate the reduced substance $\mathrm{P}$ transmission in this projection (see above).

In addition to increasing enkephalin transmission onto spiny neurons projecting to the VTA, the dopamine lesions increase D2 dopamine receptor binding (Creese and Snyder, 1979) and the electrophysiological and behavioral responses to D2 receptor 
stimulation (Breese et al., 1987; Hu et al., 1990). Moreover, the response of spiny cells to D2 receptor stimulation depends on concurrent D1 receptor tone (White, 1987), but after dopamine depletion the D2 receptors respond independently from D1 receptor tone (Hu et al., 1990). These data offer an explanation for the continued obligatory involvement of the pallidal projection in dopamine-induced behavioral activation, because D2 receptors are located preferentially in spiny cells projecting to the VP ( $\mathrm{Lu}$ et al., 1998).

\section{Adaptations in the VP after dopamine depletion in the nucleus accumbens}

DAMGO or AMPA microinjection into the VP stimulates locomotion (Austin and Kalivas, 1990; Shreve and Uretsky, 1991), and this motor response was blunted in subjects sustaining dopamine lesions in the nucleus accumbens. The motor response to AMPA or DAMGO in the VP is blocked by coadministration of muscimol (Shreve and Uretsky, 1991; Alesdatter and Kalivas, 1993). Therefore, the increased basal GABAergic tone in the VP of dopamine-depleted subjects (Bourdelais and Kalivas, 1992) may mediate the blunted behavioral response to AMPA and DAMGO in the VP. Also, the reduction in $\mu$-opioid receptor synthesis in the pallidum may diminish the behavioral response to DAMGO further (Delfs et al., 1994).

The behavioral stimulation after DAMGO or AMPA in the $\mathrm{VP}$ is blocked by stimulating $\mathrm{GABA}_{\mathrm{B}}$ receptors in the VTA (Johnson et al., 1996). Dopamine depletion in the nucleus accumbens selectively eliminated involvement of the VTA in DAMGOinduced motor activity without altering the capacity of baclofen to inhibit the behavioral response to AMPA receptor stimulation. DAMGO-induced motor activity from the VP is blocked by inhibiting dopamine receptors in the nucleus accumbens (Austin and Kalivas, 1991). Thus, it is thought that DAMGO-induced locomotion from the VP arises in part from inhibiting GABA neurons in the VP that project to the VTA and thereby increasing mesoaccumbens dopamine transmission (Austin and Kalivas, 1991; Johnson et al., 1996). By lesioning this dopamine projection, we have found that output through the VTA and mesoaccumbens dopamine system is no longer possible. Thus, after dopamine depletion the DAMGO-induced locomotion may arise from modulating other efferents from the VP (Groenewegen et al., 1993) that are known to modulate motor behavior, including projections to the subthalamus, mediodorsal thalamus, and mesencephalic locomotor region (Mogenson et al., 1985, 1993).

\section{Conclusions}

The compensatory adaptations associated with dopamine lesion in the striatum/accumbens are illustrated in Figure 8. Neuroplasticity produced by dopamine depletion alters the behavioral response to $\mu$-opioid receptor stimulation in the nucleus accumbens that is reflected by cellular plasticity within the circuit containing the nucleus accumbens, VP, and VTA and in the involvement of circuitry distal to the VP and VTA.

\section{REFERENCES}

Alesdatter JE, Kalivas PW (1993) Inhibition of $\mu$-opioid-induced motor activity in the VP by D1 receptor blockade. Behav Pharmacol 4:645-651.

Austin MC, Kalivas PW (1989) Blockade of enkephalinergic and GABAergic mediated locomotion in the nucleus accumbens by muscimol in the VP. Jpn J Pharmacol 50:487-490.

Austin MC, Kalivas PW (1990) Enkephalinergic and GABAergic modulation of motor activity in the VP. J Pharmacol Exp Ther $252: 1370-1377$.
Austin MC, Kalivas PW (1991) Dopaminergic involvement in locomotion elicited from the $\mathrm{VP} /$ substantia innominata. Brain Res 542:123-131.

Bourdelais A, Kalivas PW (1992) Apomorphine decreases extracellular GABA in the VP of rats with 6-OHDA lesions in the nucleus accumbens. Brain Res 577:306-311.

Breese GR, Duncan GE, Napier TC, Bondy SC, Iorio LC, Mueller RA (1987) 6-Hydroxydopamine treatments enhance behavioral responses to intracerebral microinjection of D1- and D2-dopamine agonists into nucleus accumbens and striatum without changing dopamine antagonist binding. J Pharmacol Exp Ther 240:167-176.

Churchill L, Kalivas PW (1992) Dopamine depletion produces augmented behavioral responses to a $\mu$-, but not a $\delta$-opioid, agonist in the nucleus accumbens: lack of a role for receptor upregulation. Synapse 11:47-57.

Churchill L, Dilts RP, Kalivas PW (1992) Autoradiographic localization of $\gamma$-aminobutyric acid $_{\mathrm{A}}$ receptors in the ventral tegmental area. Neurochem Res 17:101-106.

Creese I, Snyder SH (1979) Nigrostriatal lesions enhance striatal ${ }^{3} \mathrm{H}$-apomorphine and ${ }^{3} \mathrm{H}$-spiroperidol binding. Eur $\mathrm{J}$ Pharmacol 56:277-281.

Delfs JM, Yu L, Ellison GD, Reisine T, Chesselet M-F (1994) Regulation of $\mu$-opioid receptor mRNA in rat globus pallidus: effects of enkephalin increases induced by short- and long-term haloperidol administration. J Neurochem 63:777-780.

Delfs JM, Ciaramitaro VM, Parry TJ, Chesselet M-F (1995) Subthalamic nucleus lesions: widespread effects on changes in gene expression induced by nigrostriatal dopamine depletion in rats. $\mathrm{J}$ Neurosci 15:6562-6575.

Gerfen CR, Young III WS (1988) Distribution of striatonigral and striatopallidal peptidergic neurons in both patch and matrix compartments: an in situ hybridization histochemistry and fluorescent retrograde tracing study. Brain Res 460:161-167.

Gerfen CR, McGinty JF, Young III WS (1991) Dopamine differentially regulates dynorphin, substance $\mathrm{P}$, and enkephalin expression in striatal neurons: in situ hybridization histochemical analysis. J Neurosci 11:1016-1031.

Groenewegen HJ, Berendse HW, Haber SN (1993) Organization of the output of the ventral striatopallidal system in the rat: ventral pallidal efferents. Neuroscience 57:113-142.

Groenewegen HJ, Wright CI, Beijer AVJ (1996) The nucleus accumbens: gateway for limbic structures to reach the motor system? Prog Brain Res 107:485-511.

Guttenberg ND, Klop H, Minami M, Satoh M, Voorn P (1996) Colocalization of $\mu$-opioid receptor is greater with dynorphin than enkephalin in rat striatum. NeuroReport 7:2119-2124.

Heimer L, Zahm DS, Churchill L, Kalivas PW, Wohltmann C (1991) Specificity in the projection patterns of accumbal core and shell in the rat. Neuroscience 41:89-125.

Hooks MS, Kalivas PW (1994) Involvement of dopamine and excitatory amino acid transmission in novelty-induced motor activity. J Pharmacol Exp Ther 269:976-988.

Hu XT, Wachtel SR, Galloway MP, White FJ (1990) Lesions of the nigrostriatal dopamine projection increase the inhibitory effects of $D_{1}$ and $\mathrm{D}_{2}$ dopamine agonists on caudate putamen neurons and relieve $\mathrm{D}_{2}$ receptors from the necessity of $D_{1}$ receptor stimulation. J Neurosci 10:2318-2329.

Joel D, Weiner I (1994) The organization of the basal ganglia-thalamocortical circuits: open interconnected rather than closed segregated. Neuroscience 63:363-379.

Johnson K, Churchill L, Klitenick MA, Hooks MS, Kalivas PW (1996) Involvement of the ventral tegmental area in locomotion elicited from the nucleus accumbens or VP. J Pharmacol Exp Ther 277:1122-1131.

Jones DL, Mogenson GJ (1980) Nucleus accumbens to globus pallidus GABA projection: electrophysiological and iontophoretic investigations. Brain Res 188:93-105.

Kalivas PW, Bronson M (1985) Mesolimbic dopamine lesions produce an augmented response to enkephalin. Neuropharmacology 24: 931-936.

Kalivas PW, Widerlov E, Stanley D, Breese GR, Prange Jr AJ (1983) Enkephalin action on the mesolimbic dopamine system: a dopaminedependent and a dopamine-independent increase in locomotor activity. J Pharmacol Exp Ther 227:229-237.

Kalivas PW, Churchill L, Klitenick MA (1993a) The circuitry mediating 
the translation of motivational stimuli into adaptive motor responses. In: Limbic motor circuits and neuropsychiatry (Kalivas PW, Barnes CD, eds), pp 237-287. Boca Raton, FL: CRC.

Kalivas PW, Churchill L, Klitenick MA (1993b) GABA and enkephalin projection from the nucleus accumbens and VP to VTA. Neuroscience 57:1047-1060.

Kawaguchi Y, Wilson CJ, Emson PC (1990) Projection subtypes of rat neostriatal matrix cells revealed by intracellular injection of biocytin. J Neurosci 10:3421-3438.

Lacey MG, Mercuri NB, North RA (1988) On the potassium conductance increase activated by $\mathrm{GABA}_{\mathrm{B}}$ and dopamine receptors in rat substantia nigra neurones. J Physiol (Lond) 401:437-454.

Laprade N, Soghomonian J-J (1995) Differential regulation of mRNA levels encoding for the two isoforms of glutamate decarboxylase (GAD65 and GAD67) by dopamine receptors in the rat striatum. Mol Brain Res 34:65-74.

Le Moal M, Simon H (1991) Mesocorticolimbic dopaminergic network: functional and regulatory roles. Physiol Rev 71:155-234.

Lindefors N, Brodin E, Tossman U, Segovia J, Ungerstedt U (1989) Tissue levels and in vivo release of tachykinins and GABA in striatum and substantia nigra of rat brain after unilateral striatal dopamine denervation. Exp Brain Res 74:527-534.

Lu X-Y, Ghasemzadeh MB, Kalivas PW (1998) Expression of D1, D2, substance $\mathrm{P}$, and enkephalin mRNAs in the neurons projecting from the nucleus accumbens. Neuroscience 82:767-780.

Milliken GA, Johnson DE (1984) Analysis of messy data, Vol I, Designed experiments. Belmont, CA: Lifetime Learning Publications.

Mogenson GJ, Nielsen MA (1983) Evidence that an accumbens to subpallidal GABAergic projection contributes to locomotor activity. Brain Res Bull 11:309-314.

Mogenson GJ, Jones DJ, Yim CY (1980) From motivation to action: functional interface between the limbic system and the motor system. Prog Neurobiol 14:69-97.

Mogenson GJ, Swanson LW, Wu M (1985) Evidence that projections from the substantia innominata to zona incerta and mesencephalic locomotor region contribute to locomotor activity. Brain Res 334:65-76.

Mogenson GJ, Brudzynski SM, Wu M, Yang CR, Yim CCY (1993) From motivation to action: a review of dopaminergic regulation of limbic-nucleus accumbens-VP-pedunculopontine nucleus circuitries involved in limbic-motor integration. In: Limbic motor circuits and neuropsychiatry (Kalivas PW, Barnes CD, eds), pp 193-236. Boca Raton, FL: CRC.

Olpe H-R, Koella WP, Wolf P, Haas HL (1977) The action of baclofen on neurons of the substantia nigra and of the ventral tegmental area. Brain Res 134:577-580.

Pan HS, Penney JB, Young AB (1985) $\gamma$-Aminobutyric acid and benzodiazepine receptor changes induced by unilateral 6-hydroxydopamine lesions of the medial forebrain bundle. J Neurochem 45:1396-1404.

Patel S, Slater P (1988) Effects of GABA compounds injected into the subpallidal regions of rat brain on nucleus accumbens evoked hyperactivity. Behav Neurosci 102:596-600.

Paxinos G, Watson C (1997) The rat brain in stereotaxic coordinates, Ed 3. San Diego: Academic.

Pellegrino LK, Pellegrino AS, Cushman AJ (1979) A stereotaxic atlas of the rat brain. New York: Plenum.

Shreve PE, Uretsky NJ (1991) GABA and glutamate interact in the substantia innominata/lateral preoptic area to modulate locomotor activity. Pharmacol Biochem Behav 38:385-388.

Soghomonian JJ, Gonzales C, Chesselet MF (1992) Messenger RNAs encoding glutamate-decarboxylases are differentially affected by nigrostriatal lesions in subpopulations of striatal neurons. Brain Res 576:68-79.

Stinus L, Winnock M, Kelley AE (1985) Chronic neuroleptic treatment and mesolimbic dopamine denervation induce behavioral supersensitivity to opiates. Psychopharmacology 85:323-328.

Sugita S, Johnson SW, North RA (1992) Synaptic inputs to GABA $_{A}$ and $\mathrm{GABA}_{\mathrm{B}}$ receptors originate from discrete afferent neurons. Neurosci Lett 134:207-211.

Svingos AL, Moriwaki A, Wang JB, Uhl GR, Pickel VM (1996) Ultrastructural immunocytochemical localization of $\mu$-opioid receptors in rat nucleus accumbens: extrasynaptic plasmalemmal distribution and association with leu ${ }^{5}$-enkephalin. J Neurosci 16:4162-4173.

Swanson LW (1982) The projections of the ventral tegmental area and adjacent regions: a combined fluorescent retrograde tracer and immunofluorescence study in the rat. Brain Res Bull 9:321-353.

Swerdlow NR, Swanson LW, Koob GF (1984) Substantia innominata: critical link in the behavioral expression of mesolimbic dopamine stimulation in the rat. Neurosci Lett 50:19-24.

Voorn P, Docter GJ, Jongen-Relo AL, Jonker AJ (1994) Rostrocaudal subregional differences in the response of enkephalin, dynorphin, and substance $\mathrm{P}$ synthesis in rat nucleus accumbens to dopamine depletion. Eur J Neurosci 6:486-496.

White FJ (1987) D1 dopamine receptor stimulation enables the inhibition of nucleus accumbens by a D2 receptor agonist. Eur J Pharmacol 135:101-105.

Yuan X, Madamba S, Siggins GR (1992) Opioid peptides reduce synaptic transmission in the nucleus accumbens. Neurosci Lett 134:223-228. 